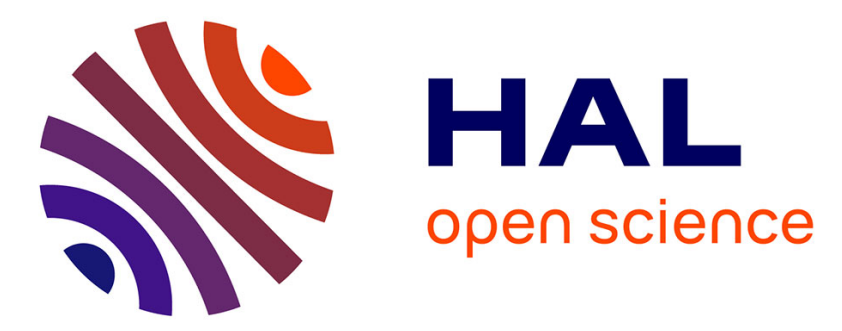

\title{
Intermittent behaviour in the Belousov-Zhabotinsky reaction
}

\author{
Y. Pomeau, J.C. Roux, A. Rossi, S. Bachelart, C. Vidal
}

\section{To cite this version:}

Y. Pomeau, J.C. Roux, A. Rossi, S. Bachelart, C. Vidal. Intermittent behaviour in the Belousov-Zhabotinsky reaction. Journal de Physique Lettres, 1981, 42 (13), pp.271-273. 10.1051/jphyslet:019810042013027100 . jpa-00231925

\section{HAL Id: jpa-00231925 https://hal.science/jpa-00231925}

Submitted on 1 Jan 1981

HAL is a multi-disciplinary open access archive for the deposit and dissemination of scientific research documents, whether they are published or not. The documents may come from teaching and research institutions in France or abroad, or from public or private research centers.
L'archive ouverte pluridisciplinaire HAL, est destinée au dépôt et à la diffusion de documents scientifiques de niveau recherche, publiés ou non, émanant des établissements d'enseignement et de recherche français ou étrangers, des laboratoires publics ou privés. 


\title{
LE JOURNAL DE PHYSIQUE-LETTRES
}

\section{Intermittent behaviour in the Belousov-Zhabotinsky reaction}

\author{
Y. Pomeau \\ J. C. Roux, A. Rossi, S. Bachelart and C. Vidal \\ Centre de Recherche Paul-Pascal, 33405 Talence, France
}

CEN Saclay, BP no 2, 91190 Gif sur Yvette and GPS, Laboratoire de Physique de l'ENS, 24, rue Lhomond, 75231 Paris, France

(Reçu le 6 mars 1981, accepté le 11 mai 1981)

\begin{abstract}
Résumé. - L'une des routes possibles vers la turbulence est la transition intermittente. Avant la transition vers la turbulence, des oscillations régulières existent et au-dessus des oscillations apparemment régulières sont interrompues au hasard par des bruits de grande amplitude. Ce comportement se manifeste dans la réaction de Bélousov-Zhabotinsky. D'autre part une analyse des mesures montre que l'on a affaire dans ce cas à une intermittence de type 1 .
\end{abstract}

\begin{abstract}
One of the possible routes to turbulence is the intermittent transition. Below the onset of turbulence regular oscillations exist, and above the onset seemingly regular oscillations are interrupted randomly by large amplitude bursts. This behaviour shows up in the Belousov-Zhabotinsky reaction. Moreover an analysis of the measurements indicates that a so-called « type 1 » transition takes place in this case.
\end{abstract}

The possibility of turbulence in chemical kinetics, as suggested by Ruelle [1], has been verified recently $[2,3]$ for the Belousov-Zhabotinsky (B-Z) reaction. We report here the discovery of an intermittent behaviour in this reaction. Such a behaviour has been seen during the transition to turbulence in thermoconvection experiments [4] and in studies of ordinary equations [5].

In our experiment, the $\mathrm{B}-\mathrm{Z}$ reaction takes place in an open well stirred tank reactor. Due to stirring, no spatial pattern can develop and the concentrations of the chemical species evolve according to the non linear equations of chemical kinetics, as derived from the mass action law; this deterministic behaviour is sufficient to produce chaos. The experimental conditions are : reacting volume $28 \mathrm{ml}$, temperature $39.6^{\circ} \mathrm{C}$, concentration of reagents before reaction in mol.1 $1^{-1}$ (standard analytical reagent grade without further purification) :

$$
\begin{gathered}
\mathrm{NaBrO}_{3}=1.8 \times 10^{-3}, \quad \mathrm{CH}_{2}(\mathrm{COOH})_{2}=5.6 \times 10^{-3}, \\
\mathrm{Ce}_{2}\left(\mathrm{SO}_{4}\right)_{3}=5.8 \times 10^{-4}, \quad \mathrm{H}_{2} \mathrm{SO}_{4}=1.5
\end{gathered}
$$

A peristaltic pump feeds the reactor at constant adjustable rate. The chemical reaction in the reactor is monitored by the optical density at $340 \mathrm{~nm}$. As this wavelength is absorbed [ 6 ] by the $\mathrm{Ce}^{4+}$ ion only, the signal is a sort of "pure quantity" and has been preferred to the redox potential that depends on the concentration of several chemical species.

As shown in figure $1 a$, when the mean residence time of chemicals in the reactor is $100 \mathrm{~min}$., the optical density oscillates regularly. At higher fluxes (residence time $76 \mathrm{~min}$. in figure $1 \mathrm{~b}$ ) the time record changes in a specific manner : seemingly stable oscillations exist which are interrupted from time to time and at random by large peaks. Such a transition from stable periodic behaviour to oscillations interrupted by random bursts denotes an intermittent transition to turbulence [5]. The present transition is well described by " type 1 intermittency " [7], shortly described hereafter. Although detailed modelizations of the B-Z kinetics have been proposed [8], we have not tried to relate them to our observations, since most features of the intermittent transition are model independent. 


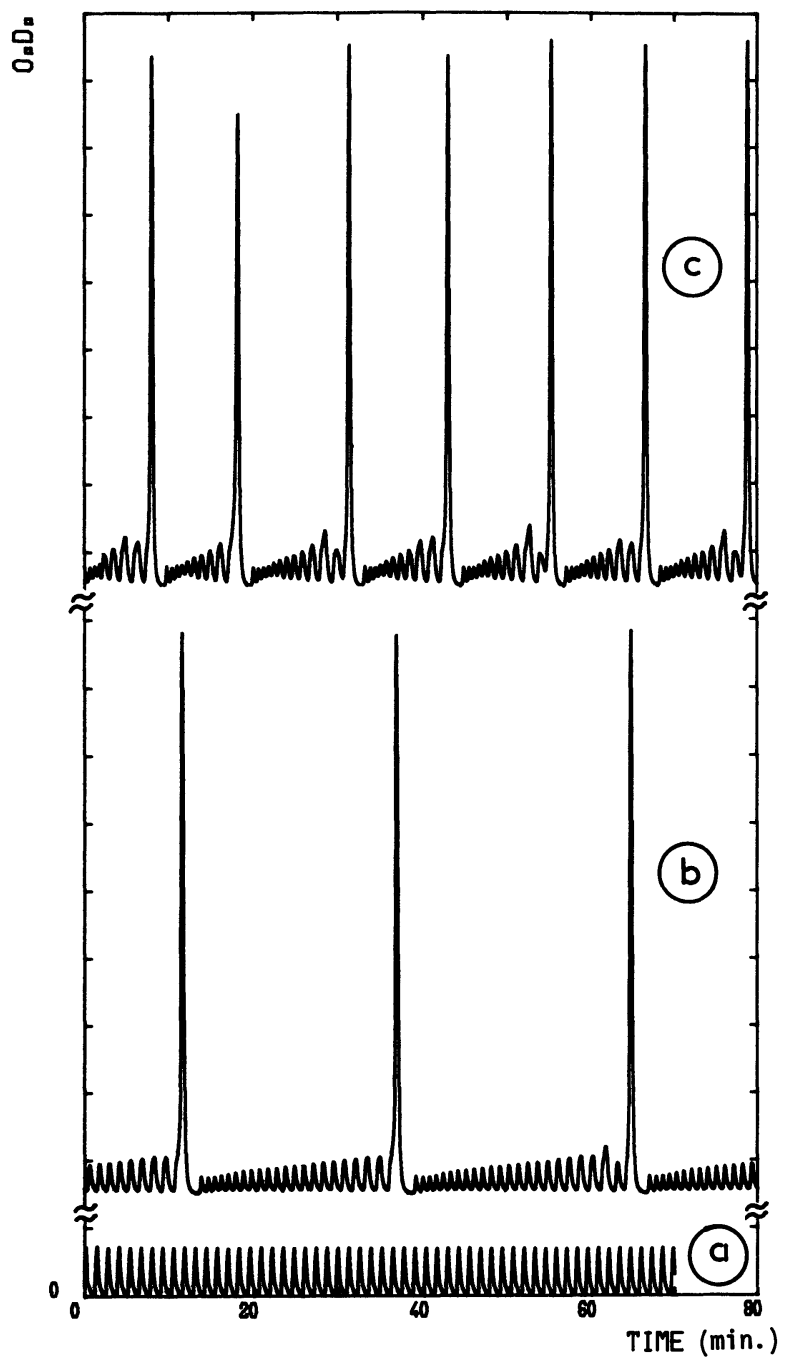

Fig. 1. $-\left[\mathrm{Ce}^{4+}\right]$ oscillations recorded as a function of time : a) residence time $100 \mathrm{~min} . ; b$ ) residence time $76 \mathrm{~min} . ; c)$ residence time $35 \mathrm{~min}$.

Following an idea already used [4b] in studying the Rayleigh-Bénard thermoconvection, we consider the peak to peak amplitude of the " regular " oscillations between two bursts; this gives ordered sequence of numbers $X_{1} \ldots X_{n}, X_{n+1} \ldots$ In type 1 intermittency, these numbers are connected to each other by a finite difference equation. This reads [7] after suitable choice of normalizations and origins in the generic form :

$$
X_{n+1}=X_{n}+\varepsilon+X_{n}^{2} .
$$

$\varepsilon$ is the control parameter, a smooth function of the residence time. For $\varepsilon<0$ (in particular for a residence time of $100 \mathrm{~min}$.), $X= \pm(-\varepsilon)^{1 / 2}$ are two fixed points of the iteration $:-(-\varepsilon)^{1 / 2}$ (resp. $\left.+(-\varepsilon)^{1 / 2}\right)$ being stable (resp. unstable). The stable fixed point corresponds to the stable oscillations before the intermittent transition (Fig. la). If $\varepsilon$ is positive, the fixed points of (1) vanish and a small channel is created [7] between the first bissectrix [in the Cartesian plane $\left(X_{n}, X_{n+1}\right)$ ] and the representative curve $X_{n+1}\left(X_{n}\right)$. This curve is locally approximated by a parabola, as implied by equation (1). Far away from the region $X \sim 0$, this local form is no longer valid; however this large distance behaviour affects the structure of the large bursts only, that we do not consider here.

For $\varepsilon>0$, starting from a negative $X$, the successive $X_{n}$ 's, as given by equation (1), drift slowly through the channel toward positive values. Plotting $X_{n+1}\left(X_{n}\right)$, as given by the time records of the $\mathrm{B}-\mathrm{Z}$ reaction in the intermittent conditions, one can recognize this drift process (Fig. 2). Furthermore, near $\varepsilon=0+$, one may replace equation (1) by a differential equation [7], $n$ being taken as continuous. This yields :

$$
X(n) \simeq \varepsilon^{1 / 2} \operatorname{tg}\left(n \varepsilon^{1 / 2}\right) .
$$

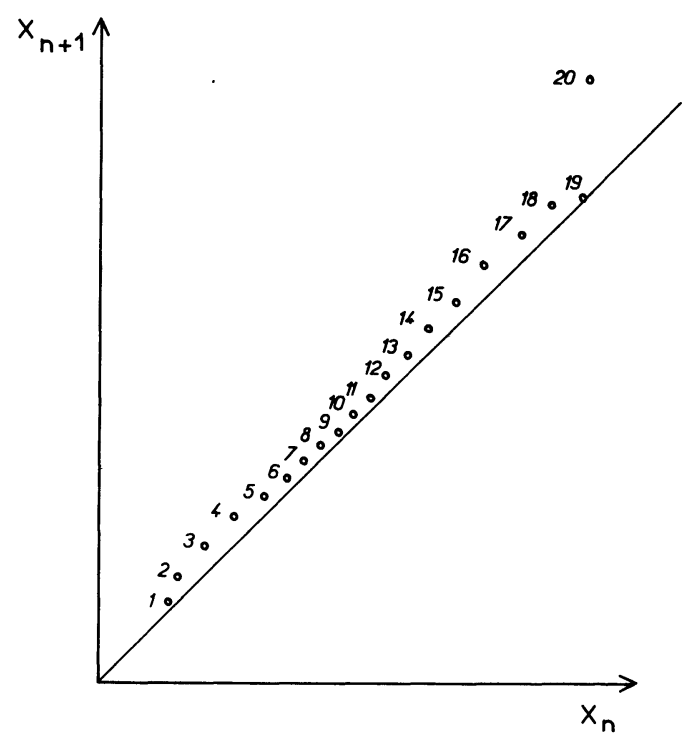

Fig. 2. - Peak to peak amplitude of the "regular" oscillations between two bursts (residence time : $76 \mathrm{~min}$.)

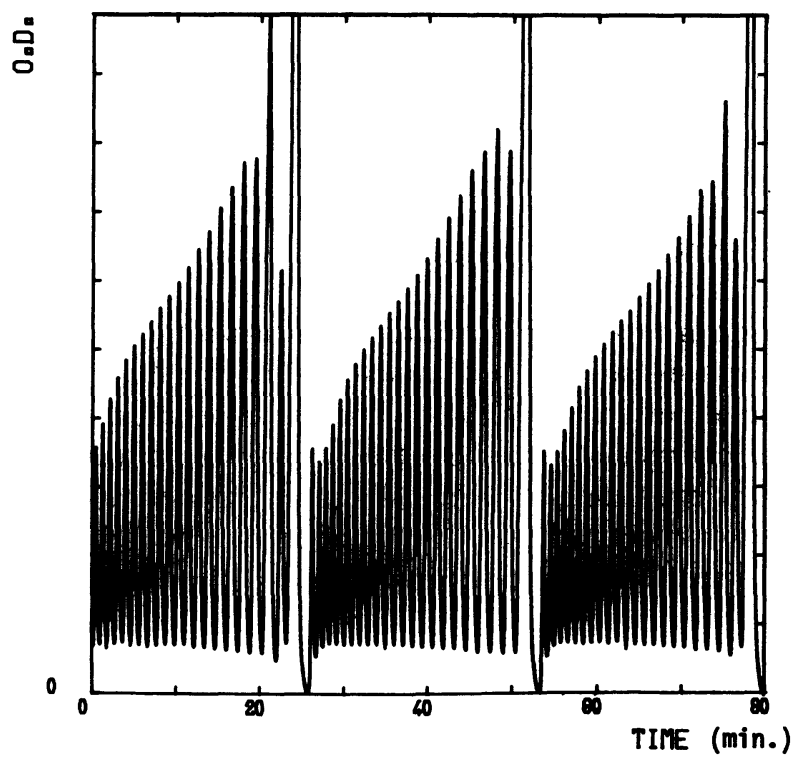

Fig. 3. - Enlarged view of the oscillations (residence time : $76 \mathrm{~min}$.). 
This approximation breaks down when $n \varepsilon^{1 / 2}$ tends to $\pm \pi / 2$. However, the tangent like shape of the local maxima can be recognized in the records (Fig. 3).

In real life experiments, it is in principle impossible to conclude surely about the stochastic or non stochastic nature of a process recorded during a finite time. Nevertheless we present hereafter more plausible arguments for our interpretation of this transition :

(i) at values of the residence time still lower than these reported here, the behaviour becomes more and more chaotic. The duration and structure of the oscillations between two bursts fluctuate more and more (Fig. 1c). This agrees with the idea that chaos is already present just beyond the onset of intermittency, even though the records look quite regular then.

(ii) the frequency of occurrence of large bursts does not seem to be locked with the frequency of fast oscillations. The number of oscillations between two bursts varies randomly, with a probability distribution shown in figure 4. This distribution is typical of "type 1 intermittency " : the time needed to drift through the channel is bounded from above. This time can fluctuate to lower values only. A two dimensional iteration scheme, as the one proposed in references $[4,6]$ yields a probability distribution similar to the one of figure 4 .

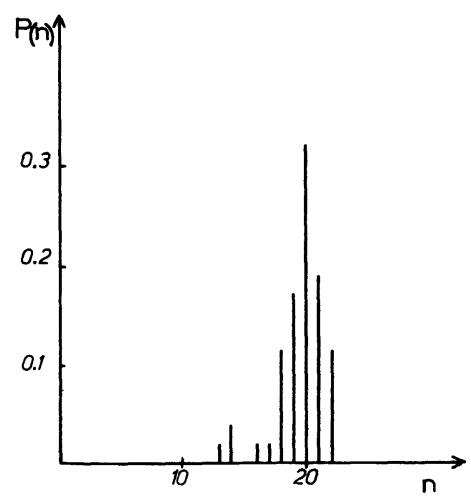

Fig. 4. - Probability distribution of the number of oscillations between two bursts (residence time : $76 \mathrm{~min}$.).

To conclude, all our experimental data are consistent with a transition to turbulence via type 1 intermittency.

\section{References}

[1] Ruelle, D., Trans. N. Y. Acad. Sci. 35 (1973) 66.

[2] a) Vidal, C., Roux, J. C., Rossi, A. and Bachelart, S., C.R. Hebd. Séan. Acad. Sci. Paris C289 (1979) 73-76 and Ann. N. Y. Acad. Sci. (1980), in press.

b) Roux, J. C., Rossi, A., Bachelart, S. and Vidal, C., Experimental observation of complex dynamical behaviour, accepted for publication in Physica D.

[3] Roux, J. C., Rossi, A., Bachelart, S. and Vidal, C., Phys. Lett. A 77 (1980) 391-393.

[4] a) Maurer, J., LibChaber, A., J. Physique Lett. 41 (1980) L-515-L-518. b) Bergé, P., Dubois, M., Manneville, P., Pomeau, Y., $J$. Physique Lett. 41 (1980) L-341-L-346.

[5] Pomeau, Y., Manneville, P., Physica D 1 (1980) 219-226.

[6] Vidal, C., Roux, J. C., Rossi, A., J. Am. Chem. Soc. 102 (1980) 1241-1245.

[7] Pomeau, Y., Manneville, P., Comm. Math. Phys. 74 (2) (1980) 189-197.

[8] Tyson, J. J., "The Belousov-Zhabotinsky reaction ", Lecture Notes in Biomathematics, vol. 10 (Springer Verlag, Berlin) 1976. 